\title{
Spatio-temporal variations in extreme drought in China during 1961-2015
}

\author{
ZHANG Jing ${ }^{1,2,3,4}$, 'SHEN Yanjun ${ }^{1}$
}

1. Key Laboratory of Agricultural Water Resources, Hebei Laboratory of Agricultural Water-Saving, Center for Agricultural Resources Research, Institute of Genetics and Developmental Biology, CAS, Shijiazhuang 050021, China;

2. University of Chinese Academy of Sciences, Beijing 100049, China;

3. Hebei Provincial Climate Centre, Shijiazhuang 050021, China;

4. Hebei Province Meteorological and Ecological Environment Laboratory, Shijiazhuang 050021, China

\begin{abstract}
Understanding the past variations in extreme drought is especially beneficial to the improvement of drought resistance planning and drought risk management in China. Based on the monitoring data of meteorological stations from 1961 to 2015 and a meteorological drought index, the Standardized Precipitation Evapotranspiration Index (SPEI), the spatio-temporal variations in extreme drought at inter-decadal, inter-annual and seasonal scales in China were analyzed. The results revealed that 12 months cumulative precipitation with $1 / 2$ to $5 / 8$ of average annual precipitation will trigger extreme drought. From the period 1961-1987 to the period 1988-2015, the mean annual frequency of extreme drought (FED) increased along a strip extending from southwest China (SWC) to the western part of northeast China (NEC). The increased FED showed the highest value in spring, followed by winter, autumn and summer. There was a continuous increase in the decadal-FED from the 1990s to the 2010 s on the Tibetan Plateau (TP), the southeast China (SEC) and the SW. During the period 1961-2015, the number of continuous drought stations was almost the same among 4 to 6 months and among 10 to 12 months of continuous drought, respectively. It can be inferred that drought lasting 6 or 12 months may lead to more severe drought disasters due to longer duration. The range of the longest continuous drought occurred in the 21 st century had widely increased compared with that in the 1980s and the 1990s. Our findings may be helpful for water resources management and reducing the risk of drought disasters in China.
\end{abstract}

Keywords: extreme drought; China; standardized precipitation evapotranspiration index; climate change

\section{Introduction}

Extreme weather and climate events are one of the most significant and increasingly attractive topics under the global climate warming background over the past few years (Easterling

Received: 2018-02-01 Accepted: 2018-05-21

Foundation: National Key R\&D Program of China, No.2016YFC0401403; Climate Change Project of China Meteorological Administration, No.CCSF201851

Author: Zhang Jing, PhD Candidate and Senior Engineer, specialized in climate change and hydrology and water resources. E-mail: 343617032@qq.com

*Corresponding author: Shen Yanjun, Professor, E-mail: yjshen@sjziam.ac.cn 
et al., 2000; Cook et al., 2014). Drought, especially extreme drought, can cause considerable damage to crop yield, human economies, people's livelihood and property, and even influence the social stability of nations (Cook et al., 2014; Kelley et al., 2015; Lesk et al., 2016). According to the hydro-meteorological disaster reports, the global drought-induced grain output dropped by an average of 10.1\% from 1964 to 2007 (Lesk et al., 2016). A significant change in extreme droughts in the second half of the 20th century had affected many parts of the world (Frich et al., 2002). The southern U.S., northern Mexico and the Central Great Plains experienced extreme drought in the summers of 2011 and 2012 (Wang et al., 2014a). The crop yield of the U.S. in 2012 fell $26 \%$ below the expected yield, which was the largest crop failure since 1866 (Hoerling et al., 2014). The drought in Syria between 2007 and 2010 was the most serious drought in history, resulting in a large crop failure and a large-scale migration of farmers into urban centers (Kelley et al., 2015). Moreover, previous studies predicted the risk of drought could increase in the 21st century by using climate model simulations on soil moisture (Sheffield, 2008) and drought indices (Dai, 2013).

China is one of the countries that experience the most frequent and serious drought in the world. Extreme drought often causes serious natural disasters, imposing a great threat on agricultural production and people's livelihood in China (Li et al., 2012). Drought caused direct economic losses accounting for $21.2 \%$ of the total losses caused by all types of weather and climate disasters, which is only second to floods losses (Qin, 2015). About 17\% of the grain total output (70-80 billion $\mathrm{kg}$ ) was lost caused by drought per year on average in China (Liu et al., 2013a). During 1991 to 2009, the frequency of drought was about $79.21 \%$ recorded by national wheat meteorological stations of China, which was higher than other nine types of agro-meteorological disasters (Zhang et al., 2014). The winter drought in 2008-2009 led to a loss of nearly 16 billion Chinese yuan in northeast China and more than 10 million people faced water shortages (Wang et al., 2011). In recent decades, drought has also occurred in southern China, especially in southwest China (Qiu, 2010; Xu et al., 2015). Extreme drought is getting more and more attention given that the pressures on resources, environment and ecology increase along with the global climate change and the rapid economic development of China. Moreover, the inter-decadal variations in the frequency of extreme drought (FED) events are more uneven than that of moderate drought events in China (Li et al., 2012). However, few studies have focused on quantifying and explicitly analyzing the spatio-temporal variations and trends of extreme drought, which are prerequisites for drought risk management and China's planning of drought disaster resistance. Extreme drought is a small probability event that occurs when water deficit is severe. Compared to all levels of droughts, extreme drought often suffers severe drought disasters. Moreover, all levels of droughts do not necessarily result in disasters, which affect the accuracy of drought assessment. Therefore, analysis of the variations in extreme droughts can improve understanding of major drought events and drought management.

Various drought indices have been developed for drought monitoring and drought assessment. However, there is as yet no unique and universally accepted droughts indicator that we can identify its impacts on different systems, such as agriculture, water resources and ecosystems (Heim, 2002). Some studies compared the differences between the Standardized Precipitation Index (SPI) and the Palmer Drought Severity Index (PDSI), which are commonly used for analyzing the spatio-temporal patterns and variations in meteorological droughts (Jain et al., 2014; Ren et al., 2014). To some extent, the SPI is better and more 
sensitive than the PDSI in reflecting meteorological droughts, soil moisture variations and extreme droughts events (Keyantash and Dracup, 2002; Lloyd-Hughes and Saunders, 2002). The Standardized Precipitation Evapotranspiration Index (SPEI), which is based on precipitation and evaporation demand, combines the multi-scalar characteristic and simple calculation of the SPI with the sensitivity of the PDSI to temperature changes (Vicente-Serrano et al., 2010; Yu et al., 2014). Moreover, the SPEI is more sensitive to potential evapotranspiration (PET), especially in arid regions (Cook, 2014). Based on the hypothesis of log-logistic distribution of samples, Wang and Chen (2014) confirmed the reliability of the SPEI with Thornthwaite equation (Thornthwaite, 1948) in most of China, except in western and boreal China of less than 3-month time scale in winter. Moreover, by comparing the distribution of the SPEI with the Historical Dataset in China (MICMB, 1981) in typical years, the SPEI can accurately describes the geographic center, extent and intensity of several major drought events in China (Wang and Chen, 2014). As the Thornthwaite potential evapotranspiration method is mainly applicable to wetland limitations, Zhao et al. (2015) used the calculation of evaporation from the Penman-Monteith equation proposed by the Food and Agriculture Organization (FAO) (Allen et al., 1998) to assess the applicability of SPEI in China. The modified method was also presented in the modified SPEI poposed by Beguería et al. (2014). The SPEI based on Penman-Monteith equation applied to national drought assessment performed well at both yearly and monthly time scales, making up the shortcomings in the applicability of the original SPEI in winter at a short time scale level in arid region (Liu and Jiang, 2015; Zhao et al., 2015). In addition to reflecting the meteorological droughts, the SPEI is also a reasonable index for assessing droughts conditions in agriculture, water resources and vegetation etc. (Potop et al., 2012; Stagge et al., 2015).

Numerous studies have pointed out changes in the frequency and intensity of extreme climate events, but most of these studies have been focused on extreme precipitation or temperature. Variations in extreme drought in China have received less attention, and most studies on extreme drought have concentrated on the regional analysis (Lu et al., 1962; Yang et al., 2013; Zhang et al., 2015). From the autumn of 2009 to the spring of 2010, extreme drought was encountered in southwest China due to abnormally low precipitation and high temperature anomalies (Lu et al., 1962). The inter-annual and inter-decadal trend of extreme drought events had gradually decreased from 1960-2013 in the Huaihe River Basin (Zhang et al., 2015). Yang (2013) detected that the extreme severe drought events had a tendency of gradual increase in China, mainly due to the obvious aridity in northern China in the second half of the 20th century. Since almost all severe drought disasters are associated with long-term continuous or extreme drought, the evolutionary process of extreme drought in space and time is an important aspect in the field of drought research. With global warming, increased attention to the hydrological cycle raises the question as to whether extreme drought is truly increasing in China and how extreme drought has changed in different regions.

In this study, we analyzed the spatio-temporal patterns and variations in extreme drought at inter-decadal, inter-annual and seasonal scales in China by using the monitoring data of meteorological stations from the period of 1961-2015 with the SPEI based on Penman-Monteith equation. The objectives of the study are: 1) to understand the spatial distribution of critical annual precipitation when extreme drought happened as well as the spatial differences of average annual and seasonal variations in the FED between the period of 
1988-2015 and 1961-1987; 2) to exhibit temporal variations in the inter-decadal and inter-annual changes in the FED for different subareas during 1961-2015; 3) to explore the annual changes in the number of meteorological stations under different duration of extreme drought from 2 to 12 months respectively, and the decade of each station when the longest extreme drought duration occurred during 1961-2015. The conclusions of the study will help to further understand the evolution of extreme drought in China. It can also provide scientific basis for the research of extreme drought mechanism and the risk management of extreme climate events.

\section{Data and methods}

\subsection{Study areas and data sources}

Due to the impact of the East Asian monsoon climate and vast territory with complicated terrain, the climate in China varies from region to region significantly. Therefore, it is relatively difficult to estimate the characteristics of climatic hazards for such a wide territory as a whole unit. In this study, considering the climate division and administrative zones, the Chinese mainland was partitioned to six subareas (Figure 1): northeast China (NEC), northwest China (NWC), northern China (NC), southeast China (SEC), southwest China (SWC) and the Tibetan Plateau (the TP). We first divided China into the NWC, the TP and eastern monsoon region according to the $400 \mathrm{~mm}$ contour line of mean annual precipitation which is an important climate demarcation line between semi-arid and semi-humid areas. The boundary of the Tibetan Plateau was adopted from the scope in Zhang et al. (2002). The other four eastern monsoon regions were divided in terms of the Qinling Mountains-Huaihe River line and administrative boundaries.

This study used the quality-proven data on daily sunshine hours, temperature (maximum and minimum temperature), wind speed, relative humidity from 824 meteorological stations, and monthly precipitation data from 756 meteorological stations from the National Meteorological Information Center of the China Meteorological Administration (CMA) (http://cdc.nmic.cn/home.do) over China during 1961-2015. Many meteorological stations in China have observational records going back to the early 1950s. However, most data from the 1950s contains large amounts of gaps due to instrument malfunctions. Considering the length, quality, continuity, homogeneity of the records and the applicability of the assumed distribution of the SPEI, 547 stations were chosen for further calculations, as shown in Figure 1. Missing data of the selected meteorological stations is inevitable for long-term monitoring. The missing data from several stations is replaced by the average of the same date or same month in other years without missing data. The fill charts were drawn with the method of kriging interpolation by using the software of ArcGIS10.

\subsection{Calculation of Standardized Precipitation Evapotranspiration Index (SPEI)}

The Standardized Precipitation Evapotranspiration Index (SPEI) based on the SPI (McKee et al., 1993) is a standardized meteorological drought index to quantify the severity of droughts conditions with consideration of water balance and spatial comparison at different time scales (Vicente-Serrano et al., 2010). The difference $D_{i}$ between precipitation $P_{i}$ and $P E T_{i}$ for the month $i$ is calculated using: 


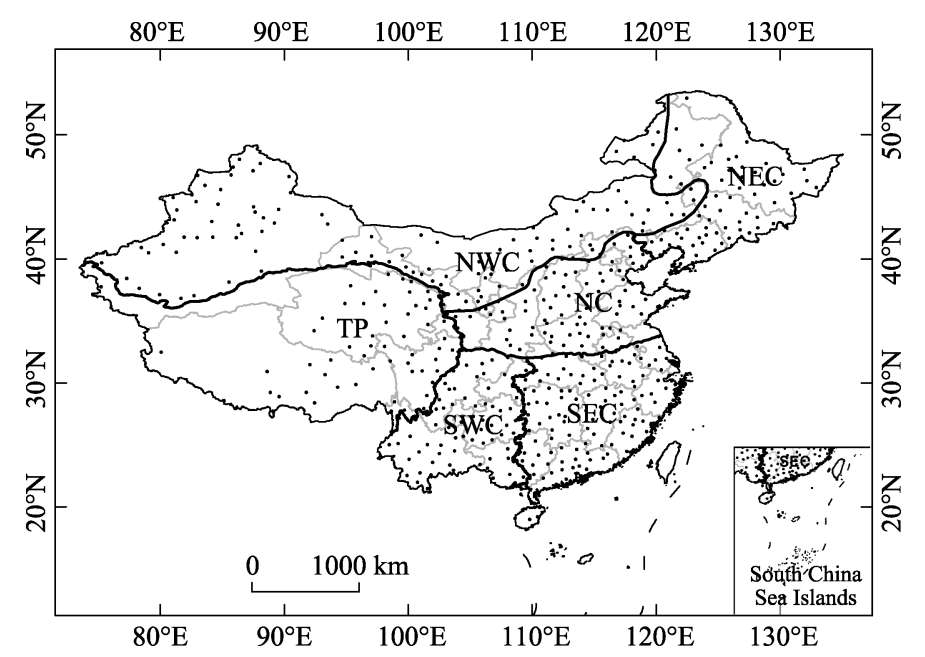

Figure 1 Locations of the 547 stations and different subareas in China: northeast China (NEC), northern China (NC), southeast China (SEC), southwest China (SWC), northwest China (NWC) and the Tibetan Plateau (the TP). The first four subareas are often regarded as the eastern monsoon regions of China.

$$
D_{i}=P_{i}-P E T_{i}
$$

The calculated $D_{i}$ is aggregated at different time scales. It is recommended to use a three-parameter log-logistic distribution for standardizing the accumulative series $D_{i}$ to obtain the SPEI at a given time scale. It calculates drought indices by standardizing the series $D_{i}$ at different time scales. The SPEI can characterize the degree of dryness/wetness deviation from normal conditions. To capture the spatio-temporal variations in drought more typically, we defined extreme drought as SPEI $\leqslant-2$ (Table 1 ) which is more closely related to drought disaster (Kelley et al., 2015). Drought duration (in months) was defined as a continuous period that SPEI is less than -1.0. By comparing the average annual SPEI and the areas of China's crops affected by drought disasters from 1961 to 2015 , the correlation coefficient of the SPEI at the 6-month time scale was higher than at other time scales. So, we selected 6-month time scale in all parts of the study except the analysis of critical precipitation as annual precipitation with 12 months scales of SPEI.

Table 1 Dryness/wetness categories according to the SPEI and the corresponding cumulative probabilities relative to the reference period (McKee et al,. 1993; Zhao et al., 2015)

\begin{tabular}{lcc}
\hline \multicolumn{1}{c}{ Categories } & SPEI classifications & Cumulative probability (\%) \\
\hline Extremely dry & $\leqslant-2.0$ & 2.28 \\
Severely dry & -1.99 to -1.5 & 6.68 \\
Moderately dry & -1.49 to -1.0 & 15.87 \\
Near normal & -0.99 to 0.99 & 50.00 \\
Moderately wet & 1.0 to 1.49 & 84.13 \\
Severely wet & 1.5 to 1.99 & 93.32 \\
Extremely wet & $\geqslant 2.0$ & 97.72 \\
\hline
\end{tabular}

Not only PDSI with different parameters (e.g. the Thornthwaite and Penman-Monteith equations) leads to discrepant results in assessing droughts (Zhang et al., 2016), the SPEI 
also faces the similar outcomes. In this study, we used the SPEI index with PET recommended by FAO, which was considered to be better monitored for the observed variations in soil moisture and stream flow in China than the SPEI based on Thornthwaite equation (Chen and Sun, 2015; Thornthwaite, 1948; Zhao et al., 2015). Considering the capability of the selected distribution over China (Wang and Chen, 2014; Zhao et al., 2015), the log-logistic distribution was tested by Kolmogorov-Smirnov test, and all the data of D series passed the significance level test of 0.05 . The reference period was the whole analysis period (1961-2015). The specific program on the website (http://digital.csic.es/handle/10261/10002) was used in this study. The critical precipitation of each station is the maximum 12 months cumulative precipitation when extreme drought (the SPEI $\leqslant-2$ ) occurs at time scales of 12 months during 1961-2015. The frequency of extreme drought (FED) in this study is defined as the ratio of the number of extreme drought months with SPEI $\leqslant-2$ to the total number of samples.

\section{Results}

\subsection{Spatial patterns of critical precipitation}

We first analyzed the spatial distribution of critical annual precipitation when extreme drought happened at 12-month time scale in the period 1961 to 2015 for 547 stations (Figure 2). It reflected the spatial differences of 12 months cumulative precipitation when extreme drought occurred under the background of local climate. The spatial distribution of critical annual precipitation presents an obvious zonal distribution. It is very similar to the spatial pattern of annual precipitation which is decreasing from southeast to northwest China. By comparing with average annual precipitation, extreme drought often happened when the cumulative precipitation was around half of local mean annual precipitation in the areas where the mean annual precipitation is less than $800 \mathrm{~mm}$. The critical precipitation is 15 to $100 \mathrm{~mm}$ in northwest China where the average annual precipitation is less than $200 \mathrm{~mm}$. Similarly, the critical precipitation is $100-200 \mathrm{~mm}$ and $200-500 \mathrm{~mm}$ respectively in the regions

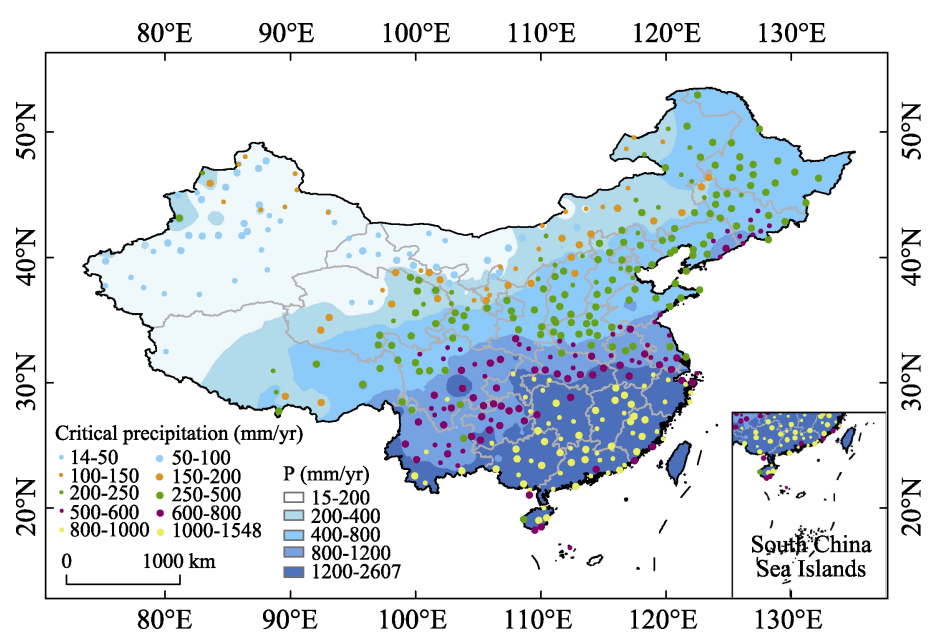

Figure 2 The critical precipitation of extreme drought (points) and the average annual precipitation (P) during 1961-2015 (the filled areas) 
where the mean annual precipitation is $200-400 \mathrm{~mm}$ and $400-800 \mathrm{~mm}$. In areas with annual precipitation over $800 \mathrm{~mm}$ (the SWC and the SEC), the critical precipitation is above half (around 5/8) of the average annual precipitation due to the relatively high temperature. Zhang et al. (2010) discovered that decreased precipitation was the key factor in drought formation in eastern China. Our results further suggest that when water and heat are both considered, precipitation plays a major role in the occurrence of extreme drought over China. The spatial distribution of critical precipitation can be used as reference information for early warning and drought mitigation measures.

\subsection{Spatial variations in the FED}

\subsubsection{Spatial variations in extreme drought frequency}

To investigate the changes of extreme drought frequency in different areas during 1961 to 2015, the differences of extreme drought frequency between the two periods of 1988-2015 and 1961-1987 were shown in Figure 3. The time segmentation method referred to the idea of Zou et al. (2005), and there was a turning point in the FED around 1987 in China as shown in Figure 5g. The regions with the increased FED by more than $2.0 \%$ were mainly in the northwest of the NEC, the northern agriculture-pasture transitional zone, the western part of the NC, the SWC and the western SEC. Yan and Yang (2000) reasoned that the aridification in northern China may come down to a decrease in the frequency of drizzles during 1951-1997. Most of the western part of China (the TP and the western part of the NWC), the eastern NEC, the NC and the SEC experienced the decreased FED. The FED had decreased by $4.0 \%-8.2 \%$ in the mid-western NWC, the northern TP and the eastern NC.

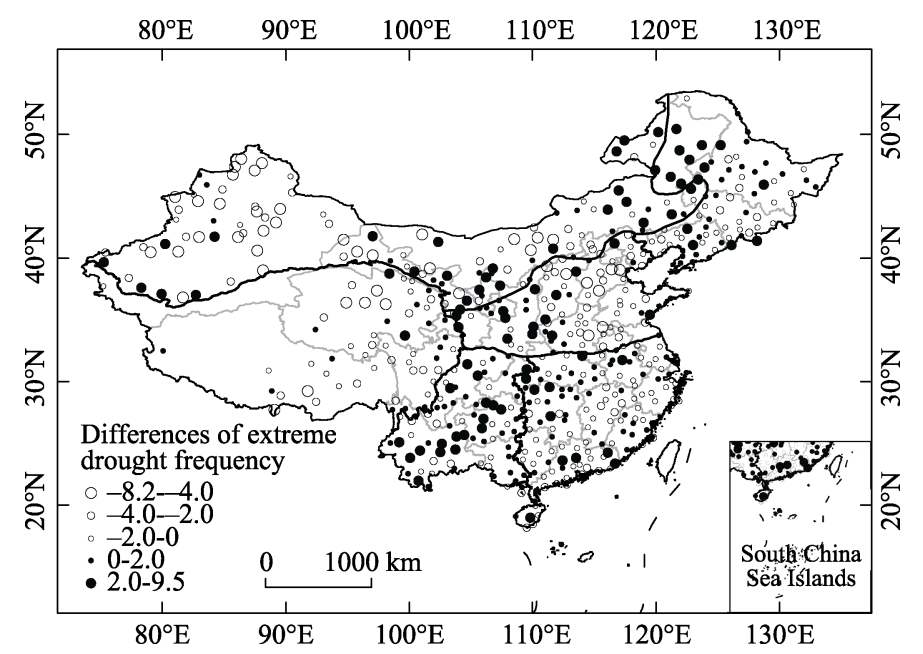

Figure 3 The differences in FED between two periods: 1988-2015 minus 1961-1987 (\%)

The increased FED mainly occurred in a strip oriented from the SWC to the western NEC, whereas a large regional decrease in FED occurred in western China (most parts of the TP and the NWC) and eastern China (eastern part of the NEC, the NC and the SEC) from 1961 to 2015. This might be related to the changes in the sea surface temperature of the tropical Pacific and the tropical Indian Ocean, leading to frequent serious drought events in the central and southwest China (Zhai et al., 2017). Zhang et al. (2015) also found that extreme drought events had gradually decreased in the Huaihe River Basin by using the Surface Hu- 
mid Index. The increase in precipitation and relative humidity significantly reduced the FED in the North China Plain (the eastern NC) from 1962 to 2011 (Liu et al., 2013b). In conclusion, areas with the increased FED were mainly concentrated in central China and the western part of northeast China. The extent of the decreased FED was larger than that of the increased FED.

\subsubsection{Spatial variations in the seasonal FED}

Figure 4 shows the average annual FED during 1961-2015 and the drought frequency variations in each station from 1961-1987 to 1988-2015 in four seasons. Generally, the FED occurred most frequently in spring. Nearly half of China suffered from spring droughts with an average annual FED of more than $2.5 \%$. There are obvious differences in the spatial distribution of the FED between 1988-2015 and 1961-1987. Extreme drought frequency decreased by more than $6.0 \%$ in most parts of the NWC and the TP, the southeast part of the NEC and the SEC. Meanwhile, the FED increased by more than $2.0 \%$ mainly in the northern NEC, the central part of the NWC, the Huaihe River Basin (the southern NC and the northern SEC) and the southwestern and central parts of the SWC.
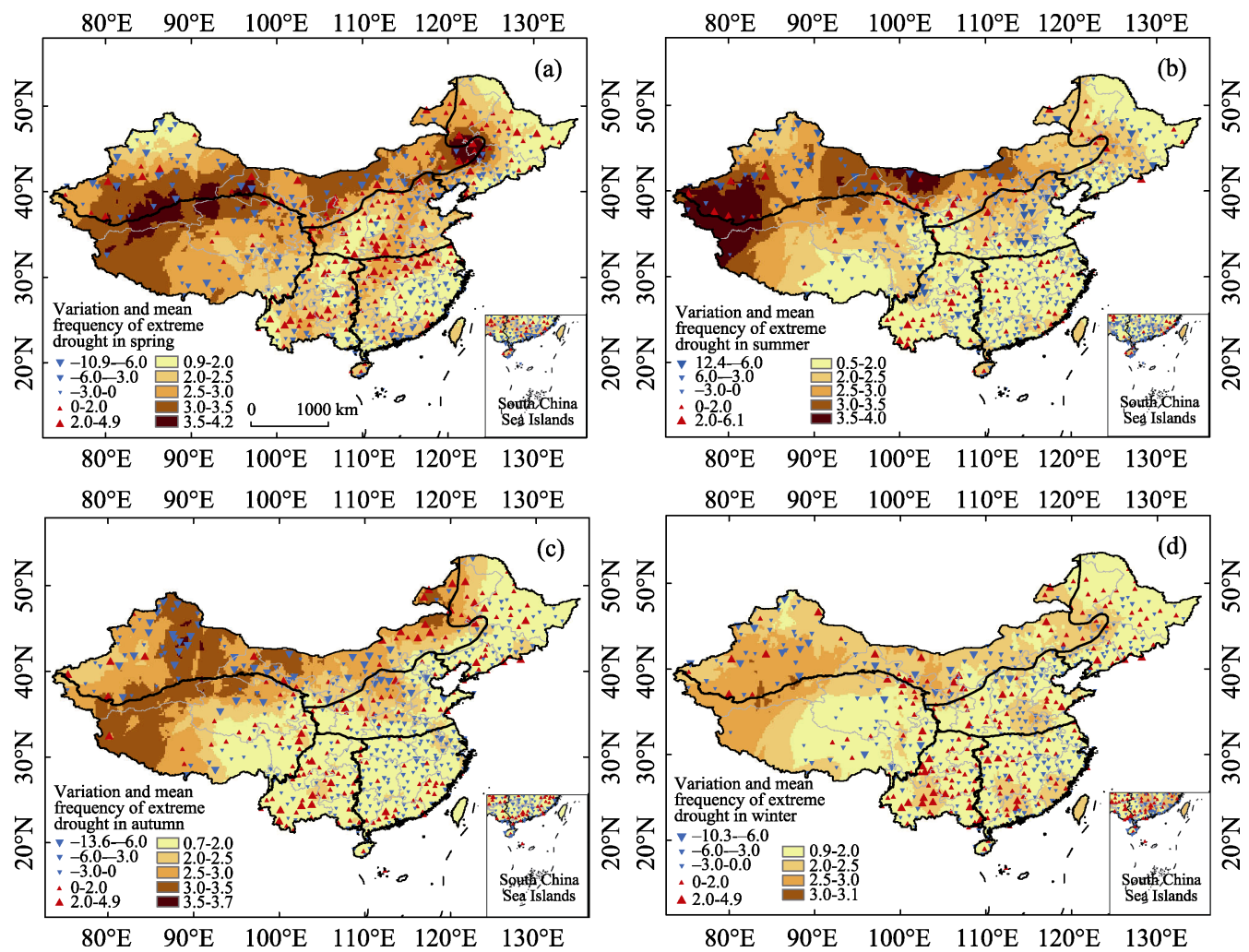

Figure 4 The average annual FED during 1961 to 2015 (shading) and the differences of extreme drought frequency between 1988-2015 and 1961-1987 (triangles) in spring (a), summer (b), autumn (c) and winter (d) (\%)

The FED in summer was generally lower than that in spring. However, the scope and severity of extreme drought frequency showed little reduction in the western NWC and the TP. It may be due to the barrier effect of the Tibetan Plateau to the warm and humid air from the southeast monsoon and southwest monsoon, leading to little precipitation in the northwest of 
China. Moreover, the high temperature of summer increased the evapotranspiration, which increased extreme drought frequency in NWC. The decreased FED appeared in most parts of China, especially in the TP, the western NWC and the eastern NC. The regions where the FED increased by more than $2.0 \%$ were mainly located in the middle of NWC and the southwestern SWC.

A gradually increased FED was presented obviously from southeast to northwest in both summer and autumn over China. Located in the mid-latitude and the east coast of Eurasia, the East Asian monsoon brings more precipitation to the eastern regions of China in summer and autumn. The regions of decreased frequency with more than $6.0 \%$ in autumn mainly occurred in the central-western NWC, the northern TP and most parts of eastern China for the period of 1988-2015 relative to 1961-1987. The intensity and extent of the extreme drought frequency had increased obviously in autumn, including the eastern $\mathrm{NWC}$, the western NEC and NC, the eastern TP and the southwestern SWC.

The FED in winter was generally the lowest in most parts of China, within $2.5 \%$, from 1961 to 2015. A significant reduction in evapotranspiration for the lowest temperature might be the major reason for the lower FED. The general decreased FED occurred in most parts of the NWC, the western TP and eastern China. The increased frequency mainly appeared in central China from the central NWC, the western NC, the SWC to the western SEC. Generally, the seasonal order of the increased FED from more to less was spring, winter, autumn and summer.

\subsection{Temporal variations in the FED}

\subsubsection{Inter-annual variations in the FED}

The average annual FED among different subareas presented commonality as well as differences from 1961 to 2015 in China (Figure 5). Most subareas and the whole of China experienced the lowest FED from the mid-1980s to the mid-1990s. Most of China had experienced a widespread extreme drought from the mid-1960s to the early 1970s. An increase in the FED occurred in the NWC, the TP, the NC, the SEC and the whole of China in the 1960s and the early 1970s. An obvious increase of the FED has occurred in the NWC, the NEC and the NC since the late 1990s and the SWC since the late 2010s. Although the highest FEDs appeared in the early 1960s in the SEC, the drought of a single year did not seem to have had serious impact. In contrast, the relatively high FED in the 1960s had a strong impact in the NC, where serious drought disasters were recorded in 1962, 1965, 1966 and 1968 in Haihe River Basin (HPFFR, 1985).

Although there has not been a substantial change in the FED in recent decades, most subareas of China experienced a decrease before around 1997. Then, a wide range of extreme drought occurred in most parts of China since the 21st century. Compared to 17 extreme drought events in China, it is consistent with the extreme drought frequency above $6 \%$ in the corresponding subareas (Ren et al., 2015). The decrease and concentration of precipitation in recent years contributed to a significant increase in the incidence of extreme drought events (Li et al., 2012).

\subsubsection{Inter-decadal variations in frequency of extreme drought}

The inter-decadal variations in severe drought disasters are closely related to the summer Asian 


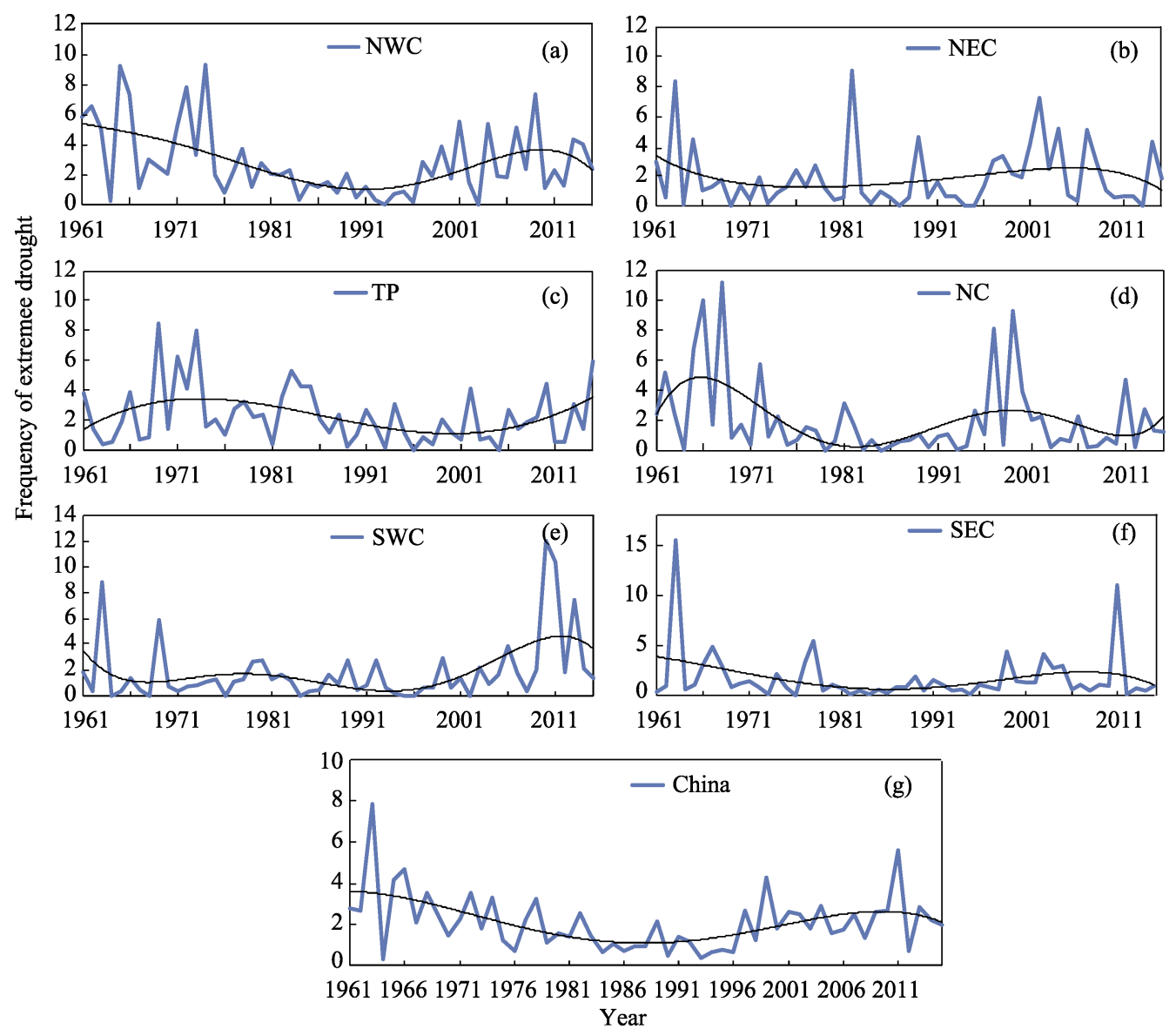

Figure 5 Time series of the average annual FED (broken lines) and 5-order polynomial fitting curves (curves) in different subareas (a-f) and China (g) during 1961-2015 (\%)

Monsoon, which caused significant changes in summer precipitation patterns in both East and South Asia (Ding et al., 2013). Table 2 illustrates that the highest FED for the NWC, the NC and the SEC are concentrated in the 1960s. This was probably due to the two weakened summer monsoon in the middle of 1960s and the late of 1970s (Huang et al., 2004). There was a continuous increase in the decadal FED from the 1990s to 2015 in the TP, the SEC, the SWC and the whole of China. This might be related to the significant decrease of winter and spring snow over the TP since the late 1990s (Si and Ding, 2013), which led to the high summer precipitation region shifting northward from the Yangtze River Basin to the Huaihe River Basin. The maximum variations between the maximal and minimal FED is more than five times in the NC, SEC and SWC, where there is a risk of high droughts and floods. The increased frequency of droughts since 2000 affecting agricultural production and frequency of drought-related disasters have been increasing and have led to growing economic losses in China (Qin et al., 2015).

\subsection{Variations in drought duration}

3.4.1 Variations in inter-annual scope of different drought duration

Different duration of continuous drought may result in different degrees of influence on 
various departments and industries. The analysis of the characteristics of different continuous periods is beneficial for the research of the laws, causes and mechanisms of extreme drought. The temporal variations in the number of meteorological stations under different duration of continuous drought from 2 months to 12 months are shown in Figure 6. There was an obvious

Table 2 Inter-decadal FED in different subareas during 1961-2015 (The upward arrow indicates changes in frequency relative to the past decade.)

\begin{tabular}{|c|c|c|c|c|c|c|}
\hline \multirow{2}{*}{ Regions } & \multicolumn{6}{|c|}{ Frequency of extreme drought $(\%)$} \\
\hline & $1960 \mathrm{~s}$ & $1970 \mathrm{~s}$ & $1980 \mathrm{~s}$ & $1990 \mathrm{~s}$ & $2000 \mathrm{~s}$ & $2010-2015$ \\
\hline NEC & 2.2 & 1.3 & 1.8 & 1.5 & $3.0 \uparrow$ & 1.3 \\
\hline NWC & 4.3 & 3.8 & 1.4 & 1.3 & $3.2 \uparrow$ & 2.6 \\
\hline $\mathrm{TP}$ & 2.4 & 3.4 & 2.5 & 1.3 & $1.9 \uparrow$ & $2.7 \uparrow$ \\
\hline $\mathrm{NC}$ & 4.3 & 1.4 & 0.8 & 2.8 & 1.0 & $1.8 \uparrow$ \\
\hline SEC & 3.2 & 1.5 & 0.6 & 1.2 & $1.7 \uparrow$ & $2.4 \uparrow$ \\
\hline SWC & 2.0 & 1.2 & 1.1 & 0.9 & $2.6 \uparrow$ & $5.9 \uparrow$ \\
\hline China & 3.2 & 2.1 & 1.2 & 1.5 & $2.2 \uparrow$ & $2.7 \uparrow$ \\
\hline
\end{tabular}
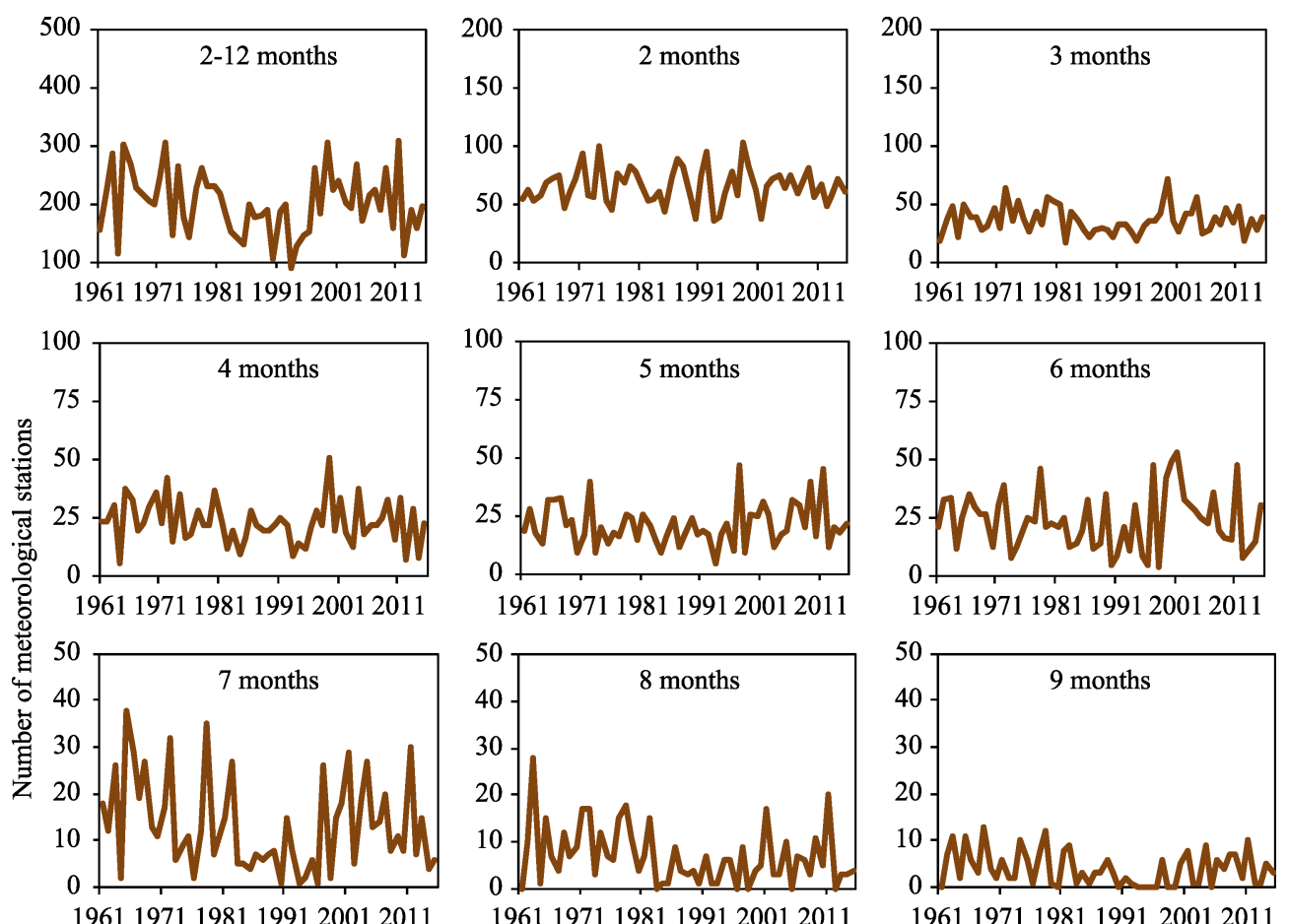

196119711981199120012011
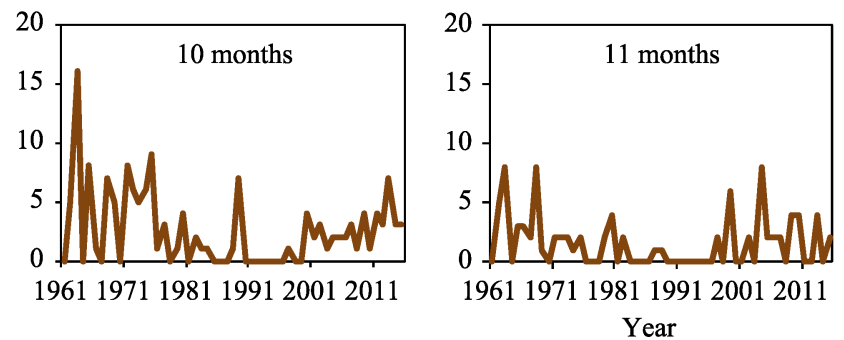

196119711981199120012011

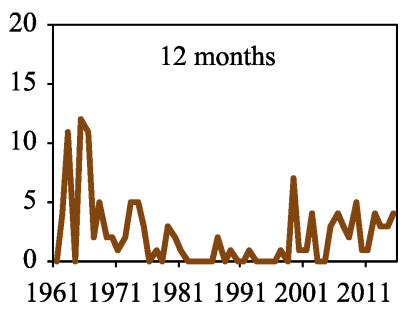

Figure 6 Time series of annual number of meteorological stations under the specific drought duration (consecutive months with SPEI $\leqslant-1.0$ ) in China during 1961-2015 
decrease of meteorological stations from the early 1980s to the mid-1990s under the total cumulative continuous periods of 2 to 12 months. The similar characteristics of continuous drought also appeared in 3 and 7 to 12 months, respectively. There were 50 to 100 stations for 2 months of continuous drought and 25 to 50 stations for 3 months of continuous drought during 1961 to 2015. From 2 months to 3 months of continuous drought, the number of stations of continuous drought had reduced by half. The double decreasing also occurred from 7 to 9 months. However, the differences in the station number of continuous drought were relatively small among 4 to 6 months with 0 to 50 stations. A similar situation also occurred from 10 to 12 months with 0 to 5 stations. It can be inferred that continuous drought of 6 or 12 months may probably lead to more severe drought disasters due to longer duration.

\subsubsection{The decades of the longest continuous drought}

In Figure 7, 385 stations were detected the sole decade of the longest continuous drought during 1961-2015 over China. The number of meteorological stations in each decade was $112,80,35,31,84$ and 43 from the 1960 s to 2010 s, respectively. The most extensive continuous drought in China occurred in the 1960s. There was no obvious regional distribution of the longest continuous drought in both the 1960s and the 1970s. The longest continuous drought in the 1980s and 1990s mainly appeared in the southern and central parts of the NEC, the Hetao area (the junction of the southern part of the NWC and the northwest NC) and the western SEC. There was a significant increase in the scope of the longest continuous drought in the 2000s, which mainly occurred in the NEC, the SWC and the eastern SEC. It is noteworthy that more than $30 \%$ of stations detected the longest continuous drought since the 2000 s, and about $50 \%$ of them occurred from 2011 to 2015 , which far exceeded the number in the 1980s or the 1990s. Compared with the extent in the 1980s and the 1990s, the areas of the longest continuous drought showed a national increase except the TP and the NC since the 21 st century.

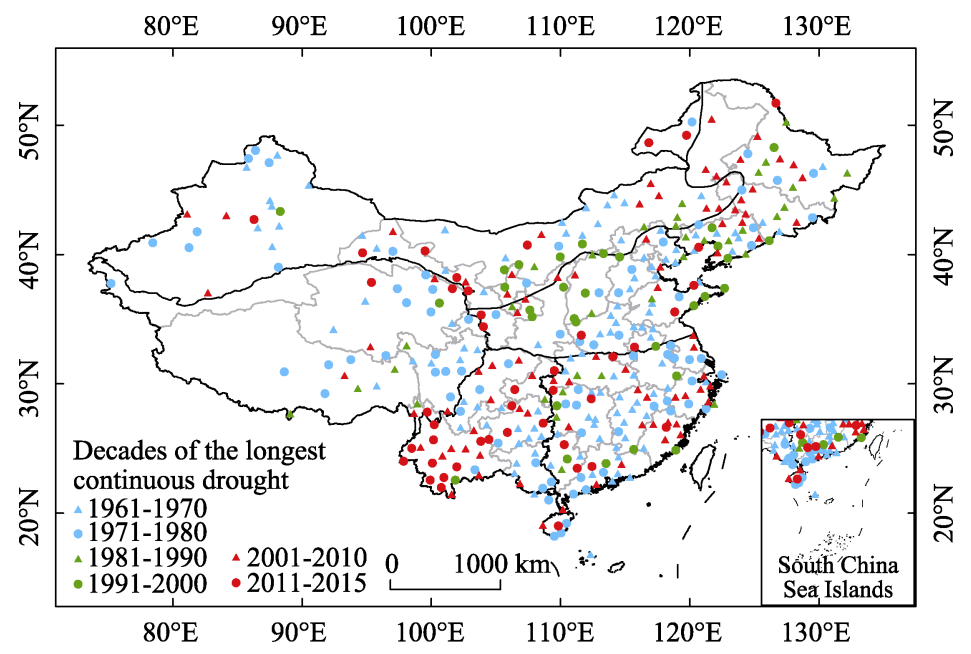

Figure 7 Decades when the longest continuous drought (SPEI $\leqslant-1)$ occurred during 1961-2015 


\section{Discussion}

Under the background of global climate warming, the frequency and intensity of drought events may probably increase in the 21 st century. Drought disasters caused by different intensity of drought events varied greatly. Droughts that caused severe drought disasters often occurred in droughts with long duration and high drought intensity (i.e. the level of extreme drought). The analysis of the spatio-temporal variations in extreme droughts will be conductive to improve the understanding of the occurrence, development, and possible causes of extreme droughts. It will also provide an important prerequisite for effective drought prevention and drought resistance. However, the existing studies had less research on the variations in extreme drought in China. This paper focuses on the occurrence and variations in extreme drought based on meteorological observation data in China.

It is worth mentioning that different conclusions are likely to be reached using different drought definitions, methods, datasets and application areas (Potop et al., 2012; Sheffield et al., 2012; Yu et al., 2014; Chen and Sun, 2015). The drying trends using the drought indices based on temperature or potential evapotranspiration calculated by Thornthwait's formula were more severe than those of methods based on FAO Penman-Monteith equation, especially in northern China (Ma and Fu, 2006; Zhang et al., 2015). Vicente-Serrano et al. (2012) also found that drought indices based on temperature data (such as the PDSI) were preferable for identifying drought impact on vegetation activity and growth. Drought responses were more sensitive to elevated temperature in northern China, especially in the arid regions, while relatively large responses to precipitation were found mainly in southern China (Chen and Sun, 2015). Changes in extreme climate events are often more sensitive to various climate change monitoring activities, making it more difficult to assess changes in extreme climate events than to assess changes in the mean (Cook et al., 2014). Therefore, it is a more difficult and more important problem to estimate the long-term climate change of the low probability of extreme drought than the mean state of the climate (Katz and Brown 1992; Plummer et al., 1999). An accurate method and higher-quality homogenized temperature data are important pre-conditions to detect the change and trend of extreme events accurately. By contrasting records (NBSPRC, 1995; HPFFR, 1985) of drought disaster with the FED in this study, the latter is consistent with severe drought disaster events, especially in Haihe Basin and northern China in 1962, 1965, 1966, 1968, 1972 and 1978, with extreme drought in the SPEI occurring more than 3-6 times per decade per station.

The frequency of extreme drought had changed obviously in most parts of China during the period 1961-2015. The regions where the FED increased were mainly distributed in a strip from the western part of northeast China to southwest China. The increase in the FED occurred in the western part of northeast China mainly in spring and autumn, and the increase in the northern agricultural and pastoral areas was mainly in spring. In most parts of the SWC, the FED increased significantly in spring, autumn and winter. In all, the FED of China has been the most widely distributed in spring since 1961. The FED of the NC mainly increased in the 1990s, while the FED of other subareas increased significantly since the 2000s. Moreover, it showed persistent increase in the FED in the TP, the SWC and the SEC in the 21st century. Although the widest range of the longest continuous drought occurred in the 1960 s, the fact that the markedly increase in the 21 st century are also worth noting, es- 
pecially since 2011 in most parts of the SWC and the SEC.

In this paper, the analysis of spatial and temporal changes of the extreme drought was based on the changes of the occurrence probability $(2.28 \%)$ of cumulative water deficit anomaly. The direct causes of extreme drought are the exceptionally low precipitation and the increase in potential evapotranspiration caused by a significant increase in temperature. Although drought disasters are a regional phenomenon, their occurrence is often affected by continuous large-scale circulation anomalies. The weakened trend of summer monsoons may probably lead to a long-term and widespread drought in the Yellow River basin and northern China (Zhang and Zhou, 2015). The western Pacific subtropical high to the north often leads to drought in the Yangtze River basin. In addition, the Yangtze River basin often experienced dry years when the position of the Tibetan Plateau high pressure is more easterly than the Tibetan Plateau. The FED in the TP, the SWC and the SEC exhibited a consistent persistent trend of increase in the 21 st century. It is speculated that there are certain links on droughts and floods in the three regions. The development stage of ENSO has a significant impact on the low rainfall and drought in the middle and upper reaches of the Yangtze River basin and in northern China (Ye et al., 1996). For example, the ENSO development year in 1963, 1965, 1968, 1972 and 1982 showed a high FED of extreme drought in Figure 5g. The results of this study will enhance our understanding of the variations in extreme drought in China, and the mechanism and reasons of extreme drought as well as the applicability of different time scales to various types of drought should be studied further.

\section{Conclusions}

Spatio-temporal distributions and variations in frequency of extreme drought (FED) and the longest continuous drought in China were examined during the period of 1961-2015 from inter-decadal, inter-annual and seasonal time scales in China and its six subareas. The conclusions showed that:

(1) The critical precipitation of extreme drought decreased from southeast China (more than $1500 \mathrm{~mm}$ ) to northwest China (less than $50 \mathrm{~mm}$ ) during 1961-2015. The extreme drought began to occur when the 12 months cumulative precipitation in the NWC, the NEC and the $\mathrm{NC}$ was around $1 / 2$ of the annual average precipitation, and extreme drought in the SWC and the SEC usually occurred when the cumulative precipitation was less than $5 / 8$ of the mean annual precipitation. Therefore, the annual precipitation was considered to be the main determinant of extreme drought occurrence in China.

(2) A drying strip stretching from the SWC to the western NEC had experienced significantly increased FED from 1961-1987 to 1988-2015. The decreased FED mainly occurred in eastern China (most areas of the TP and the NWC) and western China (western regions of the NEC, the NC and the SEC). The extent of the decreased frequency in western and eastern China was larger than that of the increased frequency which was mainly concentrated in central China and the western part of northeast China. The seasons of the increased FED from more to less were spring, winter, autumn and summer.

(3) The FED experienced a decrease before 1997, followed by a wide range of droughts since the 21 st century. The maximum frequency mainly occurred from the 1960 s to the early 1970s in the NWC, the NC, the TPC and the SEC. There was a continuous increase in the 
decadal FED from the 1990s to 2015 in the TP, the SEC, the SWC and the whole of China.

(4) The differences in the station number that documented continuous drought were relatively small between 4 and 6 months and from 10 to 12 months of continuous drought. The number of stations that documented the longest continuous drought in each decade was 114 , 78, 33, 29, 83 and 42 from the 1960s to the 2010s. Compared with the 1980s and 1990s, the number of meteorological stations of the longest continuous drought had an increased distribution since the 21 st century.

\section{Acknowledgements}

The authors express their gratitude to the National Meteorological Information Center of China Meteorological Administration (CMA) and the Spanish National Research Council for providing data and the program for calculating the SPEI, respectively. We are grateful to Dr. Qiang Zhang, Dr. Fumin Ren and Dr. Leilei Min for the careful review and valuable suggestions of the manuscript. The authors also get the help and modification suggestions from Dr. Yongqing Qi, Dr. Ying Guo, Dr. Yucui Zhang, Dr. Yanfang Wang, Dan Zhou, and Xifang Wu. The authors would also like to thank the anonymous reviewers and editors for their constructive and helpful comments and suggestions.

\section{References}

Allen R G, Pereira L S, Raes D et al., 1998. Crop Evapotranspiration: Guidelines for Computing Crop Water Requirements. FAO Irrigation and Drainage Paper 56, 300.

Beguería S, Vicente-Serrano S M, Reig F et al., 2014. Standardized precipitation evapotranspiration index (SPEI) revisited: parameter fitting, evapotranspiration models, tools, datasets and drought monitoring. International Journal of Climatology, 34(10): 3001-3023.

Chen H P, Sun J Q, 2015. Changes in drought characteristics over China using the standardized precipitation evapotranspiration index. Journal of Climate, 28: 5430-5447.

Cook B I, Smerdon J E, Seager R et al., 2014. Global warming and 21st century drying. Climate Dynamics, 43: 2607-2627.

Dai A G, 2013. Increasing drought under global warming in observations and models. Nature Climate Change, 3(1): 52-58.

Ding Y L, Sun Y, Liu Y Y et al., 2013. Interdecadal and interannual variabilities of the Asian summer monsoon and its projection of future change. Chinese Journal of Atmospheric Sciences, 37(2): 253-280.

Easterling D R, Evans J L, Groisman P Y et al., 2000. Observed variability and trends in extreme climate events: A brief review. Bulletin of the American Meterological Society, 81: 417-425.

Frich P, Alexander L V, Dellamarta P et al., 2002. Observed coherent changes in climatic extremes during the second half of the twentieth century. Climate Research, 19: 193-212.

Hebei Province Drought and Flood Forecasting Project Group (HPFFR), 1985. Natural Disasters of Haihe Basin in History. Beijing: China Meteorological Press, 65-226. (in Chinese)

Heim R R Jr, 2002. A review of twentieth-century drought indices used in the United States. Bulletin of the American Meterological Society, 83: 1149-1165.

Hoerling M, Eischeid J, Kumar A et al., 2014. Causes and predictability of the 2012 Great Plains drought. Bulletin of the American Meteorological Society, 95(2): 269-282.

Huang R, Huang G, Wei Z, 2004. Climate Variations of the Summer Monsoon over China. Singapore: World Scientific Press, 213-268.

Jain V K, Pandey R P, Jain M K, 2015. Spatio-temporal assessment of vulnerability to drought. Natual Hazards, 
76: 443-469.

Katz R W, Brown B G, 1992. Extreme events in a changing climate: Variability is more important than averages. Climatic Change, 21: 289-302.

Kelley C P, Mohtadi S, Cane M A et al., 2015. Climate change in the fertile crescent and implications of the recent Syrian drought. Proceedings of the National Academy of Sciences, 112: 3241-3246.

Keyantash J, Dracup J A, 2002. The quantification of drought: An evaluation of drought indices. Bulletin of the American Meteorological Society, 83: 1167-1180.

Lesk C, Rowhani P, Ramankutty N, 2016. Influence of extreme weather disasters on global crop production. Nature, 529: 84-87.

Liu K, Jiang D B, 2014. Interdecadal change and cause analysis of extreme summer and winter droughts over China. Chinese Journal of Atmospheric Sciences, 38(2): 309-321. (in Chinese)

Liu X J, Zhang J Q, Ma D L et al., 2013a. Dynamic risk assessment of drought disaster for maize based on integrating multi-sources data in the region of the northwest of Liaoning Province, China. Natural Hazards, 65: 1393-1409.

Liu W L, Zhang M J, Wang S J, 2013b. Temporal-spatial variation characteristics of extreme drought events in North China Plain during recent 50 years. Bulletin of Soil and Water Cnservation, 33(4): 90-95. (in Chinese)

Li W G, Yi X, Hou M T et al., 2012. Standardized precipitation evapotranspiration index shows drought trends in China. Chinese Journal of Eco-Agriculture, 20(5): 643-649. (in Chinese)

Lloyd-Hughes B, Saunders M A, 2002. A drought climatology for Europe. International Journal of Climatology, 22: $1571-1592$.

Lu E, Luo Y L, Zhang R H, 2011. Regional atmospheric anomalies responsible for the 2009-2010 severe drought in China. Journal of Geophysical Research, 116(D21114). doi: 10.1029/2011JD015706.

Ma Z G, Fu C F, 2006. The basic fact of drying in northern China during 1951 to 2004. Chinese Science Bulletin, 51(20): 2429-2439. (in Chinese)

McKee T B, Doesken N J, Kleist J, 1993. The relationship of drought frequency and duration to time scales. Eighth Conference on Appiled Climatology, 17-22.

Meteorological Institute of the Central Meteorological Bureau (MICMB), 1981. The Drought and Flood Distribution Atlas over China in the Recent Five Hundred Years. Beijing: China Meteorological Press, 11-116. (in Chinese)

National Bureau of Statistics of People's Republic of China (NBSPRC), 1995. Report of the Damage Caused by Disaster in China (1949-1995). Beijing: China Statistics Press, 25-260. (in Chinese)

Plummer N, Salinger M J, Nicholls N et al., 1999. Changes in climate extremes over the Australian region and New Zealand during the twentieth century. Climatic Change, 42: 183-202.

Potop V, Možný M, Soukup J, 2012. Drought evolution at various time scales in the lowland regions and their impact on vegetable crops in the Czech Republic. Agricultural and Forest Meteorology, 156: 121-133.

Qin D H, Zhang J Y, Shan C C et al., 2015. China National Assessment Report on Risk Management and Adaptation of Climate Extremes and Disasters. Beijing: Science Press, 154. (in Chinese)

Qiu J, 2010. China drought highlights future climate threats. Nature, 465: 142.

Ren F M, Gao H, Liu L L et al., 2014. Research progresses on extreme weather and climate events and their operational applications in climate monitoring and prediction. Meteorological Monthly, 40: 860-876. (in Chinese)

Ren F, Gong Z Q, Wang Y J, 2015. China's Regional Extreme Events: Droughts, Intense Precipitations, Heatwaves and Low Temperatures. Beijing: China Meteorological Press, 41. (in Chinese)

Sheffield J, Wood E F, 2008. Projected changes in drought occurrence under future global warming from multi-model, multi-scenario, IPCC AR4 simulations. Climate Dynamics, 31(1): 79-105.

Sheffield J, Wood E F, Roderick M L, 2012. Little change in global drought over the past 60 years. Nature, 491(7424): 435-438.

Si D, Ding Y, 2013. Decadal change in the correlation pattern between the Tibetan Plateau winter snow and the East Asian summer precipitation during 1979-2011. Journal of Climate, 26: 7622-7634. 
Stagge J H, Kohn I, Tallaksen M et al., 2015. Modeling drought impact occurrence based on meteorological drought indices in Europe. Journal of Hydrology, 530: 37-50.

Thornthwaite C W, 1948. An approach toward a rational classification of climate. Geography Review, 38: 55-89.

Vicente-Serrano S M, Beguería S, López-Moreno J I, 2010. A multiscalar drought index sensitive to global warming: The standardized precipitation evapotranspiration index. Journal of Climate, 23: 1696-1718.

Wang A, Lettenmaier D P, Sheffield J, 2011. Soil moisture drought in China, 1950-2006. Journal of Climate, 24: 3257-3271.

Wang H, Schubert S, Koster R et al., 2014a. On the role of SST forcing in the 2011 and 2012 extreme U.S. heat and drought: A study in contrasts. Journal of Hydrometeorology, 15: 1255-1273.

Wang L, Chen W, 2014. Applicability analysis of standardized precipitation evapotranspiration index in drought monitoring in China. Plateau Meteorology, 33: 423-431. (in Chinese)

$\mathrm{Xu} \mathrm{K}$, Yang D, Xu X et al., 2015. Copula based drought frequency analysis considering the spatio-temporal variability in Southwest China. Journal of Hydrology, 527: 630-640.

Yan Z W, Yang C, 2000. Geographic patterns of extreme climate changes in China during 1951-1997. Climatic and Environmental Research, 5(3): 267-272. (in Chinese)

Yang P, Xiao Z, Yang J, Liu H, 2013. Characteristics of clustering extreme drought events in China during 1961-2010. Acta Meteorologica Sinca, 27: 186-198.

Ye D Z, Huang R H et al., 1996. Drought and Flood Laws and Causes of Formation in the Yangtze and Yellow River Basins. Shandong: Shandong Science and Technology Press, 61-290. (in Chinese)

Yu M, Li Q, Hayes M J et al., 2014. Are droughts becoming more frequent or severe in China based on the standardized precipitation evapotranspiration index: 1951-2010? International Journal of Climatology, 34: 545-558.

Zhai J, Huang J, Su B et al., 2017. Intensity-area-duration analysis of droughts in China 1960-2013. Climate Dynamics, 48: 151-168.

Zhang D, Zhang L, Yang J et al., 2010. The impact of temperature and precipitation variation on drought in China in last 50 years. Acta Physica Sinica, 59: 655-663. (in Chinese)

Zhang J, Sun F B, Xu J J et al., 2016. Dependence of trends in and sensitivity of drought over China (1961-2013) on potential evaporation model. Geophysical Research Letters, 43: 206-213.

Zhang L X, Zhou T J, 2015. Drought over East Asia: A review. Journal of Climate, 28(8): 3375-3399.

Zhang W, Pan S, Cao L et al., 2015. Changes in extreme climate events in eastern China during 1960-2013: A case study of the Huaihe River basin. Quaternary International, 380/381: 22-34.

Zhang Y, Li B, Zheng D, 2002. A discussion on the boundary and area of the Tibetan Plateau in China. Geographical Research, 21: 1-8. (in Chinese)

Zhang Z, Wang P, Chen Y et al., 2014. Spatial pattern and decadal change of agro-meteorological disasters in the main wheat production area of China during 1991-2009. Journal of Geographical Sciences, 24(3): 387-396.

Zhao J, Yan D F, Yang Z Y et al., 2015. Improvement and adaptability evaluation of standardized precipitation evapotranspiration index. Acta Physica Sinica, 64(4): 049202.

Zou X, Zhai P M, Zhang Q, 2005. Variations in droughts over China: 1951-2003. Geophysical Research Letters, 32: L04707. doi: 10.1029/2004GL021853. 